\title{
Factors for a successful market in longevity-indexed government bonds: A public debt management perspective \\ Received: 20th September, 2005
}

\section{Hans J. Blommestein}

is the Head of OECD's Bond Market Programme and also leads work on public debt management and government securities markets. He is also affiliated with Tilburg University (The Netherlands) as the PwC Professor of Finance. He has published numerous articles on finance, econometric methodology, regional science, the economic transformation process in formerly planned economies, and ageing and pension reform.

\begin{abstract}
This paper reviews various ways of reducing the exposure of pension funds and annuity providers to longevity risk. Based on this review, the prospects for capital market solutions by the private sector are assessed. The paper identifies a number of key obstacles to explain why a large-scale private-sector driven market in longevity products is unlikely to develop in the near future. Using these findings, the paper considers central public policy with regard to whether the government can play a significant capital market role in overcoming these hindrances. The paper argues that this public policy role is hampered by the fact that governments themselves are already exposed to significant longevity risk. This means that issuing longevity-indexed government bonds (LIBs) would further increase their current exposure. Against this backdrop, the issuance criteria commonly used by public debt managers for launching new instruments such as LIBs are identified. On this basis, the paper concludes that the prospects for a successful, large-scale market in LIBs do not seem favourable at this stage. It is also doubtful whether relatively small government issues of LIBs would suffice to create a benchmark around which large-scale capital-market solutions by the private sector could develop.
\end{abstract}

Keywords: longevity risk, private capital-market solutions, government's capital market role, issuance criteria of public debt managers, longevity-indexed government bonds (LIBS).

Hans J. Blommestein OECD and Tilburg University

Tel: +33 128710093 Email: Hans.blommestein@ oecd.org

\section{Introduction}

For most people, increased longevity is desirable. Indeed, there appears to be a sustained, long-term trend for increased longevity. Longevity is a gradual, monotone process driven by improvements in medical technology and knowledge. ${ }^{1}$ The problem of longevity for society, however, is a uncertainty about changes in the rate of longevity, as this may have an adverse impact on one's financial welfare. Uncertainty about length of life carries the risk that individuals may run out of resources, thereby forcing them to reduce their standard of living when they are old. Longevity risk $^{2}$ is also a growing financial problem for private companies and governments that manage defined-benefit (DB) pension 
Table 1: Capital sum required for 58 -year-old male wanting $\$ 35,000$ per annum

\begin{tabular}{llll}
\hline Longevity risk & Low return (5\%) & Mid return (6.25\%) & High return (7.75\%) \\
\hline $50 \%$ & $\$ 615,000$ & $\$ 544,000$ & $\$ 473,000$ \\
$20 \%$ & $\$ 790,000$ & $\$ 673,000$ & $\$ 563,000$ \\
$5 \%$ & $\$ 910,000$ & $\$ 753,000$ & $\$ 613,000$ \\
\hline
\end{tabular}

Source: 'Managing longevity risk', Paper prepared by INVESCO, December 2000.

schemes, as well as for annuity providers.

Hedging of longevity risk is therefore desirable. In the following section, this paper will review the various ways of reducing the exposure of pension funds and annuity providers to longevity risk. Based on this review, the subsequent section will then assess the prospects for capital market solutions by the private sector. Based on this analysis, the central policy issue of this paper will be assessed: is there a desirable capital market role for the government? This policy question will be subsequently discussed from the perspective of government debt managers. To this end, the paper will identify the issuance criteria for a successful market in longevity-indexed government bonds (LIBs). The concluding section discusses the prospects of a viable market in LIBs.

\section{Reducing longevity risk exposure for pension funds and annuity providers}

Uncertainty about longevity is not about the overall direction of this trend (which seems fairly certain) but rather its speed. Indeed, some scientists even speculate that in 30-50 years mankind will reach (near) immortality. Meanwhile, increasingly unpredictable life expectancy has meant longevity is placing a greater burden on pension and insurance firm liabilities. Pressure is therefore growing to find ways of matching this source of risk. The problem with longevity risk from a financial market perspective is that there is no clear mechanism to facilitate a risk transfer. Since longevity is a trend (a nonstationary process) it is difficult to interpret as an insurable event. It is largely a systemic problem because it affects all parties concerned in broadly equivalent ways. ${ }^{3}$ In essence, most longevity risk follows from the fact that actual longevity rates are larger than the longevity assumptions in long-term contracts such as pension plans and annuities. At the individual level, longevity risk can then be translated into the probability that one runs out of available resources during retirement (financial ruin). This probability of financial ruin may be significant (Table 1).

Table 1 addresses both investment risk (via three financial market scenarios: low, medium and high investment returns) and longevity risk (the risk of financial ruin). The first row in Table 1 shows the capital sum required to have $\$ 35,000$ of indexed income for a life expectancy of 22 years, for three financial market scenarios. In each scenario, however, the risk of financial ruin is approximately 50 per cent. ${ }^{4}$ Reducing this risk to 20 per cent, requires significant additional capital, depending on the investment scenario. For the case of the medium financial return scenario of 6.25 per cent, more than 23 per cent of the original investment of $\$ 544,000$ is required. A further reduction of longevity risk to 5 per cent, requires an increase in capital of more than 38 per cent.

The greatest private sector exposure to longevity risk in OECD countries is 
related to companies' DB pension schemes. Significant exposure can also be found in the annuity portfolios of life insurance companies. Governments, however, may have the largest exposure. For example, the following figures illustrate the UK situation: ${ }^{5}$

- UK life insurance companies' balance sheets: f80bn

- UK DB pension fund liabilities: £800bn

- UK Government unfunded pension commitments: estimated up to $\mathcal{E} 450 \mathrm{bn}$

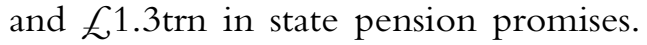

The total is larger than the country's GDP. However, it should be noted that these figures overstate the true scope of the problem as real risk exposure follows from the difference between predicted longevity rates and those which have or will actually materialise.

Transferring the longevity risk of pension funds and annuity providers can in principle take place via four principal channels: ${ }^{6}$

- protection seeker takes insurance from re-insurers;

- conversion of DB benefits to annuities via bulk 'buy outs';

- annuity provider writes balancing insurance product;

- capital market solutions.

Re-insurance companies have a fairly limited underwriting capacity. As a rule, re-insurers do not take on longevity risk, unless it is for an existing client and part of an overall package of risks, while capped at a relatively small level. ${ }^{7}$ As a result, the appetite of re-insurers for longevity risk transaction seems to be rather small at this stage, although this situation can improve with more precise knowledge of this risk and growing risk transfer demand.
In addition, the capacity of the buy-out market is rather small. The conversion of defined benefits to annuities is very expensive, while insurance capacity is very limited. Indeed, the UK buy-out market has actually shrunk, with only two major re-insurers active. ${ }^{8}$

The third way of transferring longevity risk is based on hedging through balancing products. An obvious example is the case where a holder of longevity risk would enter into a contract with a term assurance portfolio, thereby combining a conventional level annuity with a whole-life assurance to the value of the cost of the annuity. The resulting combination of the underlying risks (mortality and longevity risk) would then reduce an insurer's exposure to future increases in longevity, thereby also reducing the capital reserves held in respect of this risk (see Table 2).

The last channel for transferring longevity risk allows protection seekers to buy longevity bonds. This capital market channel will be discussed in the remainder of the paper.

\section{Prospects for large-scale capital market solutions by the private sector}

The very limited capacity of the first three channels for transferring longevity risk has prompted the search for capital market solutions. Proposed solutions for reducing the exposure to longevity risk of pension funds and annuity providers are conceptually simple, as they require the construction of capital market instruments linked to a reliable longevity index. Given a suitable index, it would be possible to construct longevity bonds with either the coupon or principal (or both) at risk of default if longevity improvements in excess of expectations occurred. ${ }^{9}$ These instruments can then be 
Table 2: Change in capital reserves after reduction of longevity risk

\begin{tabular}{lll}
\hline Increase in longevity rate & Annuity & Whole-of-life insurance \\
\hline $1 \%$ & $+3.2 \%$ & $-1.0 \%$ \\
$2 \%$ & $+6.6 \%$ & $-2.6 \%$ \\
\hline
\end{tabular}

Source: S. Richards and G. Jones (2004) 'Financial aspects of longevity risk', Paper presented to the Staple Inn Actuarial Society, London, 26th October 2005.

used to hedge ${ }^{10}$ mortality and longevity risk. Although life insurers and pension funds have similar liabilities, they have different perspectives. ${ }^{11}$ Insurance companies are concerned about potential catastrophic losses, while pension plans aim to protect corporate cash flows from incremental losses. Two examples will be discussed to illustrate the difference in underlying risks and capital market instrument.

The Swiss Re mortality bond of December 2003 offers protection against extreme mortality risks such as a flu pandemic, thereby providing short-term cover against significant 'tail risk' to their balance sheet. This short-term bond ( $\$ 400 \mathrm{~m}$, four years) has many of the features of catastrophe bonds. Principal repayments to bond holders are reduced (on a sliding scale to zero) once mortality reaches a predetermined level in excess of normal experience.

The BNP Paribas/PartnerRe/EIB long-term longevity bond will be issued by the AAA-rated European Investment Bank (EIB) and is structured as a zero coupon, 25-year amortising bond. The return depends on the number of deaths in a particular cohort of the UK male population. The coupon payments of the bond are linked to the proportion of the population who were age 65 in 2003 and who are still alive at the coupon date. A maximum payout of $\_, 50 \mathrm{~m}$ will be multiplied by the survivor index of the cohort at the coupon date; if none died, the payout is $650 \mathrm{~m}$; if 3 per cent died, the payout is 97 per cent $\times £ 50 \mathrm{~m}$, etc. It is interesting to note that this transfer of longevity risk involves two principal channels, the capital market and re-insurance. In fact, the following intermediaries are involved in this risk transfer: ${ }^{12}$

- supranational (EIB) issues longevity bond;

- protection seeker (eg pension fund) buys longevity instrument;

- supranational hedges via swap with bank;

- bank insures with re-insurer (eg via Special Purpose Vehicles (SPVs));

- re-insurer takes ultimate risk;

However, it remains to be seen as to whether this type of innovative solution will really be the beginning of a large-scale private-sector driven market in longevity products, as many structural hurdles are still in place. In fact the BNP Paribas/PartnerRe/EIB longevity bond was not well received by investors and was withdrawn for redesign at the end of 2005.

First, the crucial involvement of the re-insurer means that this capital market issue (of a relatively small scale) is in essence a transfer of longevity risk via the re-insurance channel. As noted in the previous section, the underwriting capacity in this sector is very limited, while the hedge is potentially expensive. ${ }^{13}$ There are also doubts whether additional, similar issues can be done. ${ }^{14}$

A second, even more fundamental problem is that although many parties wish to offload longevity risk (eg pension 
funds, insurance companies, governments) there are few natural buyers of longevity on the other side and none of any size (some exceptions are pharmaceutical companies, care homes, and equity release mortgages). This still looks very much like a one-way market, and is also likely to be an illiquid one, as the natural players are looking for hedging products to lock in and hold rather than trade in a secondary market. It is hard to see where general buyers and sellers will come from rather than those with specialist requirements. Added complications arise from the fact that the natural players do not necessarily want the same, homogenised product (as noted, insurance companies are looking for a hedge against catastrophic losses and pension funds to protect corporate cashflows from incremental losses). This implies further fragmentation and a lack of liquidity in any market that does develop.

The high level of uncertainty over future longevity trends is reflected in the lack of institutions prepared and able to underwrite longevity risk. At this stage the transfer of longevity risk is largely resulting in a one-way market meaning little or no market.

\section{Is there a capital market role for the government?}

Against this backdrop, could or should the government play a catalyst role in overcoming these problems? Clearly, the government can issue securities that protect the holder against greater-than-expected longevity improvements, especially at older ages (protecting the holder against statistical 'tail' risks). In a similar way, as in price-indexed government bonds, a government-sponsored longevity bond benchmark might spur the development of private sector-developed instruments.
For example, long-term longevity swaps (and options), whereby parties with offsetting longevity exposure (eg an insurance company that underwrites mainly annuities and another that underwrites mainly life insurance) would enter into a contract in order to mitigate each other's exposure to longevity risk. ${ }^{15}$ Such bonds may also increase interest in improving the mortality statistics available (eg using stochastic rather than deterministic models) so that better indexes can be developed. This would allow products to be priced more accurately and investors to buy them with more confidence.

Governments may be able to hedge longevity risk better than the private sector as they can rely on the inverse relationship between mortality rates in old age and tax revenues from the old. Yet, a key obstacle is that governments are already exposed to longevity risk via national pension and social security schemes, so issuing such securities would further increase their exposure.

What are then the technical criteria for deciding about the issuance of longevity bonds by OECD debt managers? Public debt managers use a number of assessment criteria based on, and linked to, the overall debt management objective to raise, manage and retire debt at the lowest possible price subject to an acceptable risk level. In addition, there is the derived objective of supporting domestic capital markets. ${ }^{16}$ The OECD experience with the issuance of inflation indexed-linked government bonds (ILBs) provides important guidance as to the concrete formulation of these criteria. ${ }^{17}$ The following six assessment criteria can then be identified as ways for measuring the potential contribution of LIBs to meeting these debt management objectives:

- If investors value insurance against 
unexpected increase in longevity, they need to be prepared to pay a reasonable premium for longevity-indexed debt, resulting in cheaper funding than nominal debt. As longevity risk is one of the major challenges facing pension and insurance companies, they may be prepared to pay this premium. However, it is not clear how high this premium needs to be in order to make the issuance of longevity-indexed debt attractive enough (ie cost-effective) for governments, especially in view of the fact that governments are already underwriting colossal longevity liabilities.

- Usually a proportion of the government's assets and cash flows are linked to inflation. Issuing inflation-indexed stock therefore provides an internal portfolio hedge. Unfortunately, this hedge is absent in the case of LIBs. Worse, on a total government balance sheet basis, ${ }^{18}$ the issuance of longevity-indexed instruments will increase the already high exposure of government to longevity risk.

- With inflation indexed-linked bonds, the size of budget surpluses/deficits can be smoothed, as the volatility associated with servicing real debt is lower, relative to nominal bonds. (The servicing costs are less volatile because the real flows remain fixed until maturity, whereas the flows associated with nominal bonds fluctuate with inflation.) Clearly, the servicing costs of longevity-indexed debt is more volatile than that of ILBs, with longevity-indexed flows varying with inflation.

- Issuance of ILBs provides an opportunity to diversify, both in terms of the instruments provided to investors and in terms of the investor base. In addition, the issuance of LIBs can be expected to contribute to diversification.

- Issuance of ILBs makes the market more complete, may contribute to greater efficiency in the overall market and may even encourage additional liquidity. Also, the issuance of LIBs would contribute to market completeness. But the potential for increased market liquidity and efficiency seems less clear.

- ILBs provide for a real return rate that is useful for policy makers and market participants. Similarly, returns on LIBs have the potential to provide market information on longevity risk to relevant policy makers and market participants.

\section{The prospects of a viable market in LIBS}

In sum, the potential positive contribution of LIBs to meeting debt management objectives is less obvious than for ILBs. In fact, the issuance of LIBs will increase already significant balance sheet risks for the government associated with increased longevity.

In addition, it is necessary to resolve a number of important difficulties related to market practicalities such as indices, types of indexation and the ability of small markets for LIBs to act as benchmark and catalyst. Indices need to be developed so they can be embedded in LIBs. As these indices provide the benchmark against which future mortality will be measured, they need to be simple and transparent, based on robust data, statistically credible, and calculated in an unbiased manner. ${ }^{19}$ Another practical problem is related to market scepticism around the stochastic mortality models to predict future mortality.

The prospects for a large issuing programme of longevity government bonds, therefore, do not seem favourable 
at this stage. The success of a thriving, liquid market in ILBs is in part due to the continued commitment of governments to maintain steady and significant issue streams of ILBs, thereby maintaining a critical market mass. It is therefore doubtful whether relatively small government issues of LIBs would suffice to create a benchmark around which large-scale capital-market solutions by the private sector could develop.

\section{Acknowledgements}

A first version of this paper was presented at the 'Seventh Annual OECD-World Bank Global Bond Market Forum', held on 23-24 May 2005 in Washington DC, and benefited from comments by participants. The author is indebted to Fiona Stewart for answering questions and for providing background information, but remains responsible for any errors. Moreover, the opinions expressed are personal and cannot be attributed to the OECD or its member countries

\section{References}

1 It has even been argued that technological progress has produced a radically new form of human evolution; see Blommestein, H. J. (2004) 'After the death of Utopia', The Economic Times, India, 22 March and http://www.project-syndicate.org.

2 Note that longevity risk (a loss if mortality fails to materialise) is different from mortality risk (a loss if morality increases). Moreover, longevity risk is long-dated trend risk, while mortality risk is quite spiky (volatile) and driven by short-term event; see Morgan Stanley (2005) 'Challenges to market development', Presentation at the First International Conference on Longevity Risk and Capital Market Solutions, 18th February, London.

3 Hanif, F. (2005) 'Longevity risk: The scale of the problem', Presentation at the First International Conference on Longevity Risk and Capital Market Solutions, 18th February, London.

4 This implies that about half of all 58-years old can expect to live longer than 22 years. Because of the skewed nature of the mortality experience, this is in actual fact not exactly 50 per cent.

5 Figures estimated by Adair Turner, Chairman of the Pensions Commission (2005) 'UK takes 2.4 trillion risk on long life', Timesonline, 8th April.

6 Schroeder, T. and Clark, D. (2005) 'What are the key factors that will drive the longevity bond market?', Paper presented at the Seventh Annual OECD-World Bank Global Bond Market Forum, 23-24 May, Washington DC; Richards, S. and Jones G. (2004) 'Financial aspects of longevity risk', Paper presented to the Staple Inn Actuarial Society, 26th October 2005, London; Morgan Stanley, ref. 2 above.

7 Richards and Jones, ref. 6 above.

8 Byrne, A. and Harrison, D. (2005) 'Is longevity risk a one-way market?', Report of the First International Conference on Longevity Risk and Capital Market Solutions, 18th February, London.

9 Richards and Jones, ref. 6 above.

10 This is likely to be a partial hedge as in practice significant basis risk - a portfolio of annuitants or members of pension plans or insurance schemes may exhibit a very different pattern of longevity improvements compared with the underlying index for a bond - will remain in portfolios or pension and insurance schemes. For example, Francis Fernandes argues that basis risk could be of the order of 20 per cent; see Fernandes, F. (2005) 'Longevity bond: A pension fund perspective', Presentation at the First International Conference on Longevity Risk and Capital Market Solutions, 18th February, London.

11 Roberts, P. (2005) 'A practical framework for facilitating longevity risk transfer', Presentation at the First International Conference on Longevity Risk and Capital Market Solutions, 18th February 2005, London.

12 Schroeder T. and Clark D. (2005) 'What are the key factors that will drive the longevity bond market?', Paper presented at the Seventh Annual OECD-World Bank Global Bond Market Forum', 23-24 May, Washington DC.

13 The cost of the embedded longevity hedge is $20 \mathrm{bp}$.

14 Byrne and Harrison (ref. 8 above, p. 5) note that '... PartnerRe appears to have made it clear that it has little appetite for additional deals'.

15 See also the discussion of hedging via the balancing of products in the section on prospects for large-scale capital market solutions by the private sector.

16 This objective is 'derived' as it is a means to the end of lowest borrowing costs.

17 Blommestein, H. J. (2002), ed., Public Debt Management and Government Securities Markets in the 21st Century, OECD, Paris, provides a state-of the-art overview of recent trends and major changes in the structure of government securities markets and public debt management operations in the OECD area.

18 Blommestein, H. J. (2005) 'Issues in government balance sheet risk management: a public debt management perspective', Paper presented at Sovereign Asset and Debt Management: Towards pro-active, integrated management of national assets and liabilities, 21-21 June, London, Organised by: Central Banking Publications (CBP) and forthcoming in a volume on public debt management by CBP.

19 Roberts, P. (2005) 'A practical framework for facilitating longevity risk transfer', Presentation at the First International Conference on Longevity Risk and Capital Market Solutions, 18th February, London. 